Gerión. Revista de Historia Antigua

ISSN: 0213-0181

http://dx.doi.org/10.5209/geri.65977

\title{
Aristóteles, Alejandro y la politeía griega
}

\author{
Francisco Javier Gómez Espelosín ${ }^{1}$
}

Recibido: 6 de marzo de 2019 / Aceptado: 12 de junio de 2019

Resumen. La relación entre Aristóteles y Alejandro resulta especialmente problemática debido a la falta de testimonios y a la aparente distancia que separaba a los dos personajes. La existencia de una carta atribuida al filósofo traducida al árabe podría contribuir a llenar este aparente vacío al incluir una serie de consejos dirigidos al monarca en un momento clave de la campaña de conquista. Las dificultades del texto invitan, sin embargo, a considerar la posible separación intelectual y emotiva de los dos personajes como una realidad.

Palabras clave: politeia; ciudad; tiranía; buen gobierno; filosofía.

\section{[en] Aristotle, Alexander and the Greek Politeia}

\begin{abstract}
The relationship between Aristotle and Alexander the Great is particularly difficult to perceive due to the lack of sources and the likely differences in their respective way of thinking. A letter attributed to Aristotle and preserved in an Arabic translation could radically change the question. It advices on the right way of governing the new empire, which seems to fill this blank space. The problems concerning the authenticity of the text show, however, the existence of a true gap between both figures.
\end{abstract}

Keywords: Politeia; City; Tyranny; Good Govern; Philosophy.

Sumario. 1. Introducción. 2. El testimonio de Plutarco. 3. Aristóteles como tutor de Alejandro y sus implicaciones. 4. Tras los pasos de Plutarco. 5. La carta de Aristóteles. 6. Aportación de la carta al debate. 7. Conclusiones. 8. Referencias bibliográficas.

Cómo citar: Gómez Espelosín, F. J. (2019): Aristóteles, Alejandro y la politeía griega, en Gerión 37/2, 343-362.

1 Universidad de Alcalá.

E-mail: franciscoj.gomez@uah.es 


\section{Introducción}

La relación entre Aristóteles y Alejandro constituye un tema fascinante que ha suscitado gran atención desde la Antigüedad hasta nuestros días. La implicación emocional e intelectual entre el gran conquistador macedonio y uno de los grandes filósofos ha sido siempre lo suficientemente tentadora como para servir de tema de reflexión y especulación con el fin de extraer de ella toda clase de implicaciones morales y políticas, hasta el punto de convertirse en uno de los elementos tópicos de la ficción histórica posterior sobre la biografía del legendario conquistador macedonio. ${ }^{2}$ Sin embargo, la realidad es que apenas contamos con datos solventes que avalen no solo el contenido concreto de las enseñanzas impartidas y su perduración posterior en las acciones de Alejandro, sino incluso la realidad de la propia relación, como tutor y alumno, puesta ya en entredicho por algunos estudiosos. ${ }^{3}$ Esta relativamente sorprendente escasez de datos no ha supuesto un serio obstáculo a la hora de reconstruir el entramado de tan prometedora relación entre un joven monarca lleno de aspiraciones, dispuesto a la conquista del orbe, y el gran filósofo que habría intentado siempre modelar y encauzar el poderoso y turbulento carácter de tan precoz y extraordinario discípulo.

El episodio suele figurar dentro de las recreaciones biográficas habituales y se ha recurrido a todo tipo de especulaciones a la hora de rellenar ese vacío, como intentar determinar la clase de enseñanzas que el filósofo griego pudo haber impartido en su día al joven príncipe macedonio, imaginar incluso la existencia de una continuada relación epistolar entre ambos durante todo el proceso de conquista, y proyectar la posible incidencia de tales principios y preceptos sobre la conducta general del monarca y sus futuras acciones de gobierno. ${ }^{4}$

\section{El testimonio de Plutarco}

El principal soporte que alienta toda esta apasionante fabulación acerca de la estrecha relación habida entre los dos personajes es un célebre pasaje de la Vida de Alejandro escrita por Plutarco, dado que es el único de los principales relatos conservados que desarrolla con cierto detalle la cuestión, pasada por alto por el resto de testimonios o dejada simplemente como una mera alusión. ${ }^{5}$ Según el relato de Plutarco, fue Filipo quien mandó traer a Aristóteles, que entonces se hallaba en Lesbos, para cumplir este cometido, le concedió espléndidos honorarios por dicha misión y, para que pudiera desarrollar su tarea, le asignó un lugar de retiro apartado de la capital, en Mieza,

Pérez-Simon 2010.

Chroust 1973, 125-132.

4 Sobre las relaciones entre Aristóteles y Alejandro, Düring (1957, 284-299) reúne las fuentes disponibles al efecto. Las principales especulaciones sobre dicha relación son las de Ehrenberg 1938, 62-102 y Jaeger 1946, 141-145. Sobre la clase de enseñanzas impartidas se pronunció sobre todo Merlan (1954). Schachermeyr (1949, 70-72) atribuyó a Aristóteles el interés de Alejandro por la geografía e incluso el origen de su famoso póthos. En sentido contrario, además de Chroust 1973, véase Natali 2013, 42-52. Un prestigioso estudioso de Aristóteles como Barnes $(1987,19)$ habla incluso de la imposibilidad de "atravesar el velo de la leyenda y descubrir hasta qué punto influyó Aristóteles en su ambicioso y detestable pupilo".

5 Plu. Alex. 7-8. Ni Diodoro, ni Arriano, ni Quinto Curcio mencionan el asunto y Justino solo alude a él de forma pasajera (Just.12.6.17: condiscipulatu apud Aristotelen; 12.16.8: exacta pueritia per quinquennium sub Aristotele doctore, inclito omnium philosophorum crevit). 
donde todavía en tiempo de Plutarco podían verse los bancos de piedra y los paseos umbrosos que servían de marco a sus enseñanzas. Probablemente Plutarco visitó el lugar y recibió allí algunas informaciones al respecto cuyo estricto valor como fuente histórica no debió de superar en mucho la retórica interesada y chauvinista de sus habitantes.

De hecho, más allá de la experiencia basada en su propia actividad "turística", Plutarco se ve obligado a recurrir a la especulación propia o a considerar como tal la información recibida a la hora de concretar el tipo de enseñanzas recibidas por Alejandro. Plutarco introduce la noticia mediante el uso de un verbo como éoika (parecer) que implica necesariamente un grado más o menos elevado de probabilidad pero que no comporta en modo alguno la presencia de una certeza incuestionable. Apunta así a enseñanzas de carácter moral (ethikón) y político (politikón), además de a su participación en lecciones secretas y más profundas, definidas por los filósofos como acroamáticas y epópticas, que no traspasaban el círculo de los iniciados, impartidas generalmente por vía exclusivamente oral. Utiliza como fuente de información una carta del conquistador macedonio dirigida a Aristóteles en la que se quejaba de la difusión por escrito de tales enseñanzas a cargo del filósofo, por haberle arrebatado de este modo su pretendida superioridad en ese terreno. La ambigua respuesta de Aristóteles para consolar al monarca de su decepción-que se habían publicado sin haberlo hecho en realidad- es interpretada por Plutarco en el sentido de que tales escritos tan solo tenían utilidad para los discípulos que ya se hallaban iniciados en ellos, entre los que cabe imaginar que se encontraba el propio Alejandro. Sin embargo, parece más bien una forma más o menos ingeniosa de salir del paso.

Plutarco atribuye a las enseñanzas de Aristóteles el gusto particular por la medicina que mostraba Alejandro y, aunque no de forma tan explícita, parece atribuirle también su afición por la literatura y la lectura, dado su particular amor por la Ilíada, de la que poseía una edición a cargo de Aristóteles que llevaba siempre consigo, compartiendo un espacio privilegiado bajo su almohada al lado de su espada según el testimonio de Onesícrito. ${ }^{6}$ Plutarco concluye el pasaje afirmando, por un lado, la admiración y el amor que Alejandro profesaba hacia Aristóteles, dado que, echando mano al parecer de las propias palabras del monarca, le había enseñado a vivir de la manera apropiada, y, por otro, dando también cuenta del progresivo deterioro en sus respectivas relaciones, que transformó la vivacidad afectuosa inicial en una cierta suspicacia por parte del monarca, una clara demostración del distanciamiento de su antiguo maestro.

Todo el pasaje en cuestión, analizado en detalle, adolece de una cierta ausencia de perspectiva histórica, que se inicia con la valoración de Aristóteles como "el más ilustre y sabio de los filósofos", hecha claramente a posteriori, cuando en aquellos momentos todavía no se había convertido en la figura incuestionable que más tarde llegó a ser, a pesar de que ya contaba con indiscutibles méritos. La elección de Aristóteles estuvo posiblemente fundamentada en otro tipo de condicionantes que el lustre de su currículum filosófico, que posiblemente Filipo no era capaz de apreciar en su justa medida. La presencia del todavía joven filósofo en Macedonia podría explicarse por otra clase de motivaciones, como la política seguida desde hacía tiempo por sus monarcas consistente en atraer hasta la corte de Pela a una serie de

6 BNJ 134 F 38. Parece que solo la información acerca de la existencia de una edición de la Ilíada que siempre llevaba consigo es la que hay que atribuir al historiador. 
intelectuales griegos bajo el incentivo del mecenazgo con el propósito de legitimar su carácter helénico y, en el caso particular de Filipo, de aparecer como un auténtico patrocinador de la cultura griega dentro de su campaña de propaganda tendente a enmascarar su hegemonía sobre los estados griegos. ${ }^{7}$ Plutarco prosigue después con un frágil ensamblaje de suposiciones e hipótesis, fundamentadas en sus propios prejuicios al respecto, aplicados de forma retroactiva a una época mal documentada, y avaladas además por una fuente de información tan debatida y poco solvente como la supuesta correspondencia entre los dos personajes, considerada por la mayoría de los estudiosos como elaboraciones espurias posteriores con escasa relevancia sobre la realidad histórica. ${ }^{8}$

Da la impresión, en efecto, de que Plutarco ha elaborado su retrato de la educación de Alejandro echando mano de diversas fuentes de información, englobando así dentro de un mismo contexto nombres más desconocidos como los del acarnanio Lisímaco, el de Leónidas, pariente de su madre Olimpíade, cuya implicación efectiva en la formación del joven príncipe se reconoce más adelante en el propio relato de Plutarco, y el de un personaje de la talla de Aristóteles que, si no ya entonces, desde luego más tarde alcanzaría una mayor fama y proyección que los dos personajes mencionados. ${ }^{9}$ La presencia de Aristóteles en la corte macedonia y su conexión más o menos clara con la casa real a través de su padre, que había ejercido como médico al servicio de Amintas III, el abuelo de Alejandro, facilitaron su inclusión dentro de este importante apartado en la perspectiva de Plutarco, interesado en destacar este aspecto de su personaje como una forma más de helenizarlo y proceder a su oportuna "desmacedonización". ${ }^{10}$ Sin embargo, la tradición contemporánea más antigua, al menos la que ha llegado hasta nosotros, no se hace eco de la vinculación educativa de Aristóteles con Alejandro. Tanto Onesícrito, que parece haber dedicado gran espacio a la educación y formación de Alejandro, como Marsias de Pela, que figuró entre los compañeros del futuro monarca y habría compartido con él esta experiencia, no hacen referencia al papel de Aristóteles en este campo. ${ }^{11}$

\section{Aristóteles como tutor de Alejandro y sus implicaciones}

Peter Brunt ha mostrado sus reticencias acerca del papel que pudo haber desempeñado Aristóteles en la formación filosófica de Alejandro, calificando la afirmación de Plutarco acerca del ardor demostrado en este terreno por el monarca y su admiración por su maestro como "a romantic fantasy". ${ }^{12}$ Brunt sugiere que la tarea fundamental de Aristóteles habría sido supervisar la educación física y literaria de su joven alumno, sin que tuviera la oportunidad de poder adentrarse en una formación filosófica más o menos reglada, a la vista de la edad del príncipe, que debía tener 13 o 14 años en aquel entonces, y de las exigencias y las limitaciones de tiempo

\footnotetext{
Brunt 1993, 294-295. Sobre Filipo y los intelectuales griegos, Worthington 2008, 120-122.

8 Un resumen de la cuestión en Hamilton 1961 y 1969, LXV-LXVI. En contra de la veracidad como fuentes de las cartas, Pearson 1954. Una consideración reciente, más favorable, a este respecto en Monti 2016.

Sobre Lisímaco y Leónidas: Berve 1926, II, 235-236 (Leónidas) y II, 241 (Lisímaco).

10 Hammond 1993, 165-167; Asirvatham 2018, 360.

11 Chroust 1973, 125-126. Tanto Eduard Zeller (1879) como Olof Gigon (1958), mostraron ya su extrañeza en este sentido a la hora de asegurar con pleno fundamento esta circunstancia de la biografía de Aristóteles.

12 Brunt 1993, 296.
} 
impuestas desde el ámbito estrictamente político y militar, que requerían la constante atención de un posible heredero al trono. ${ }^{13}$ De hecho, la sorprendente precocidad de Alejandro aparece ilustrada con otros motivos mucho más pragmáticos que los relacionados con sus actividades intelectuales o de carácter filosófico, como su célebre doma del caballo Bucéfalo o su temprana curiosidad por aspectos puramente geográficos y estratégicos del imperio persa, con la que sorprendió a los embajadores enviados hasta la corte macedonia. ${ }^{14}$

Las perspectivas de convertir a Alejandro en un individuo versado en cuestiones de índole filosófica se vieron inevitablemente limitadas por su condición de heredero al trono macedonio, impulsado más a sumergirse en los numerosos problemas de toda clase que rodeaban el reino que en profundas reflexiones como las que podían suscitarse en el terreno de una educación meramente intelectual. Quizá su propio carácter tampoco le predisponía a ello, si atendemos al testimonio del sofista Alexino de Élide, que escribió una generación después de Aristóteles y de forma no muy favorable hacia él, cuando afirma que mientras Alejandro era todavía un muchacho, en conversación con su padre, mostraba su evidente desdén por las doctrinas (lógoi) de Aristoteles. ${ }^{15}$ Las profundas divergencias de carácter entre maestro y discípulo pudieron hacer perfectamente inviable la empresa educativa, tal y como la concebía Aristóteles, incluso ya en el curso de estos primeros años de contacto, una disparidad que luego se manifestaría de forma notoria con el desarrollo de la campaña de conquista y el tratamiento dispensado a Calístenes, que además de pariente compartía también con Aristóteles muchas otras convicciones filosóficas e intelectuales. ${ }^{16}$

Resulta igualmente significativo el absoluto silencio de Aristóteles acerca de Alejandro en toda su obra conservada, sin que pueda encontrarse en toda ella el más mínimo rastro de la relación habida en su día con el que fue primero príncipe y luego monarca macedonio. Ni siquiera se detectan a lo largo de su obra indicios evidentes del impacto producido por la eclosión de nuevos conocimientos obtenidos en el curso de la expedición asiática. A diferencia de Teofrasto, en cuya Investigación sobre las plantas han quedado reflejados los avances en este terreno del conocimiento como resultado de los descubrimientos efectuados durante la campaña ${ }^{17}$ en la Investigación sobre los animales aristotélica todo apunta hacia etapas anteriores a la conquista a la hora de explicar el origen de las informaciones pertinentes. ${ }^{18} \mathrm{La}$ idea acerca del patronazgo científico de Alejandro sobre las investigaciones de Aristóteles, expuesta sobre todo por Plinio, que habría comportado el estrecho contacto entre ambos durante el curso de la expedición con el envío de especímenes de todo tipo para su estudio, ha quedado desmontada acertadamente por el trabajo de James Romm. ${ }^{19}$ Los problemas que preocupaban y ocupaban el pensamiento de Aristóteles no parece que tuvieran mucho que ver con los intereses más inmediatos de Alejandro. La conquista y posterior gestión de grandes territorios que implicó la

13 Incluso dentro de una visión optimista al respecto, como la que presenta Guthrie (1993, 49-51), el autor se ve obligado a reconocer la escasez del tiempo disponible para ello y la seria interrupción para las horas de estudio que significó su acceso como regente del reino.

14 Plu. Alex. 5 (Alejandro y los embajadores persas) y 6 (Bucéfalo).

15 Conocemos la noticia a través del testimonio de Aristocles recogido en Eus. PE. 15. 2. 4.

16 Sobre la relación de Aristóteles y Calístenes: Chroust 1973, 83-91; Prandi 1985, 12-25.

17 Véanse a este respecto las monumentales obras de Bretzl 1903 y Fraser 1994.

18 Sobre las diferencias entre los dos autores a este respecto, Stevens 2016.

19 Plin. NH 8.4. Romm 1989. 
expedición asiática no ocupan lugar alguno en los escritos conservados del filósofo, que quizá parecía más interesado por todo lo concerniente a los asuntos internos de los estados griegos que por cuestiones directamente relacionadas con el reino macedonio, que dentro de la concepción de Aristóteles no figuraba para nada dentro del ámbito helénico. ${ }^{20}$

Resulta también muy significativo a este respecto que apenas tengamos noticias sobre los dos tratados que el filósofo habría dedicado a Alejandro en aquellos momentos. El denominado Sobre la realeza (Perí basileías) fue quizá compuesto en el momento del acceso de Alejandro al trono de Macedonia y se desconoce su contenido efectivo a pesar de que se le adscriben algunos consejos de índole general que aparecen de forma dispersa en la tradición posterior. ${ }^{21}$ Es probable, como señala Brunt, que su contenido no fuera más allá de una serie de consejos de carácter prudencial y moral muy generales, al estilo de los que figuran en tratados como los que Isócrates dirigió en su momento a los gobernantes chipriotas. ${ }^{22}$ El titulado Alejandro o sobre los colonos o las colonias (Aléxandros e huper apoíkon e apoikión) resulta todavía mucho más problemático a la hora de decidir acerca de su contenido preciso o sobre su fecha de composición. ${ }^{23} \mathrm{Su}$ temprana desaparición y la ausencia de huellas visibles en la tradición conservada indican quizá el escaso interés que ambas obras despertaron en el que era en principio su principal destinatario, que parece haberlas ignorado por completo, lo que pudo haber contribuido a favorecer su pérdida a la vista del notorio fracaso de sus objetivos iniciales. Es muy probable que, a tenor de estas posibles constataciones, como sugiere Brunt, Aristóteles aprovechara su estancia en Macedonia para proseguir con sus investigaciones dadas las condiciones de su apacible retiro temporal y los importantes emolumentos recibidos por una tarea que ni el escaso tiempo disponible por las ocupaciones de su discípulo ni su adecuada predisposición a recibirlas permitieron llevar a buen puerto de acuerdo con sus iniciales expectativas. ${ }^{24}$

\section{Tras los pasos de Plutarco}

Esta pertinaz cortina de silencio que envuelve la posible relación personal, intelectual y afectiva entre los dos personajes dentro de la escasa tradición contemporánea, que nos resulta más o menos accesible, provocó desde muy temprano el deseo de rellenar dicha laguna a través de diferentes procedimientos más o menos ingeniosos o

20 Brunt 1993, 334-336. De hecho, en Pol. 1324 b, los macedonios aparecen listados entre los pueblos no griegos. Greenwalt (2010) ve, en cambio, una clara referencia a la monarquía macedonia en el quinto de los tipos que Aristóteles establece en la Política (3.10.2).

21 El tratado en cuestión es mencionado por Diógenes Laercio (4.14 y 5.22) y aludido en Cicerón (Cic. Att. 12.40.2 y 13.28.2). Se le adscriben el consejo que figura en Temistio 8.107c-d sobre la necesidad de que el rey escuche y se deje persuadir por los filósofos genuinos que encuentre en su camino, y el que aparece formulado en Plutarco (Plu. Mor. 329 b) y en Estrabón (Str. 1.4.9) sobre su distinto comportamiento con griegos y bárbaros, tratando a los primeros como su líder y a los segundos como su dueño. Sobre dicha obra, Weil 1960, 157-159.

22 Brunt 1993, 297.

23 D.L. 5.22. Tanto Ross (1955) como Laurenti (1987) adscriben a dicha obra el consejo acerca del tratamiento diferenciado dispensado a griegos y bárbaros al que se ha hecho referencia anteriormente. Véase Weil 1960, 154-157; Laurenti 1987, 911-959.

24 Brunt 1993, 296. 
imaginativos. ${ }^{25}$ El testimonio de Plutarco en este sentido constituye un ejemplo más de esta imperiosa necesidad. A ella responde también la existencia de algunos textos dentro del extenso corpus aristotélico que pretenden haber tenido a Alejandro como destinatario privilegiado, como la Retórica a Alejandro o el Tratado sobre el cosmos para Alejandro, ambas de autenticidad más que problemática aunque parece claramente descartada por completo su autoría aristotélica. ${ }^{26}$ Ese mismo papel han desempeñado también las diferentes cartas atribuidas a los dos personajes, particularmente a Aristóteles, algunas de ellas utilizadas por el mismo Plutarco como testimonio para su reconstrucción de los hechos, que presentan igualmente serios problemas a la hora de garantizar su posible autenticidad con un cierto consenso sobre su carácter espurio. ${ }^{27}$

El intento de Plutarco por dar contenido y consistencia a una circunstancia aparentemente tan prometedora como podía haber sido la relación entre Aristóteles y Alejandro se basa posiblemente en tradiciones helenísticas posteriores, deseosas de establecer un estrecho vínculo entre los dos personajes ante las acusaciones vertidas contra el filósofo de haber participado en el envenenamiento del rey o de priorizar su influencia y sus enseñanzas frente a las pretensiones de escuelas filosóficas rivales, que derivaban las inclinaciones filosóficas de Alejandro hacia corrientes cínicas o estoicas, como refleja el propio Plutarco. ${ }^{28}$ Dicha tendencia ha proseguido después con cierta convicción por parte de algunos estudiosos modernos. Uno de los ejemplos más sobresalientes es quizá el de Werner Jaeger, empeñado en demostrar la estrecha relación de las ideas de Aristóteles con el proyecto de Alejandro, al menos en sus primeras etapas ${ }^{29}$. Jaeger concede una gran importancia a la relación del filósofo con la corte del tirano Hermias de Atarneo como elemento decisivo a la hora de trasladar a Aristóteles a Macedonia y expresa su firme convicción de que "se daba perfecta cuenta de que estaba formando las ideas del heredero del estado dirigente de Grecia, el reino europeo más poderoso de la época". Convencido Aristóteles de que Grecia podía dominar el mundo si estuviera políticamente unida y de que solo la "eminente personalidad del verdadero rey, que pudiera ver en Grecia su propia encarnación" podía superar la tradicional desunión de los estados griegos, trabajó de forma decidida en esta dirección. El estudioso alemán detecta la influencia de Aristóteles en el "grado notablemente alto de conciencia personal e histórica de sí" que tenía el joven monarca macedonio, de quien el filósofo esperaba "que condujera a los griegos a la unidad y sentara el dominio de ellos en el este sobre las ruinas del imperio persa". Reconoce, sin embargo, que la pérdida del diálogo Alejandro o sobre la colonización "nos ha ocultado lo que más nos hubiera gustado saber -el efecto de este cambio en el escenario de la historia universal sobre el pensamiento político de Aristóteles". ${ }^{30}$

25 Bröcker 1966.

26 Sobre el primero de ellos, véase la reciente edición a cargo de Pierre Chiron en Belles Lettres (2002), y sobre el segundo la de Giovani Reale y Abraham Bos 1995.

27 Se encuentran en Rose (1886, frg. 651-670) y Plezia (1961; 1977). Incluso en la edición de Gigon (1987) no existe una sección dedicada en concreto a las cartas. Al respecto, un resumen de la cuestión en Natali 2013, 122-124.

28 Al respecto, Chroust 1973, 130-132. Sobre las relaciones entre Alejandro y la filosofía: Mensching 1963; Giannantoni 1988; y en general, Stoneman 2003.

29 Jaeger 1946, 142-145

30 Jaeger 1946, 298. 
La imposibilidad de encontrar apoyo para sus optimistas teorías acerca de la posible y beneficiosa influencia de Aristóteles sobre Alejandro en el escaso reguero dejado por la mención de dos obras de las que apenas sabemos nada ha llevado a la mayor parte de los estudiosos a buscar con ahínco y dedicación dentro de la Política los elementos necesarios, inevitablemente abstractos ya que nunca se menciona el nombre de Alejandro en el curso de la obra, que permitan promocionar esta clase de ideales. Uno de estos pasajes es aquel en el que Aristóteles destaca la existencia de un individuo excepcional dentro del estado que sobrepasa tanto en virtud al resto que no puede parangonarse con ellos para concluir que sería considerado como un dios entre los hombres a causa de esta superioridad indiscutible por su capacidad y peso político. ${ }^{31}$ Ya desde Hegel se supuso que Aristóteles tenía a Alejandro en mente en dicho pasaje, en lo que parece a todas luces como una defensa o justificación de una monarquía de carácter absoluto. ${ }^{32}$ Sin embargo, no parece en modo alguno que exista una conexión de esta clase dentro de un marco teórico que, situado siempre dentro del universo de la polis, excluía por completo cualquier injerencia exterior de esta clase. $^{33}$

\section{La carta de Aristóteles}

Dentro de este panorama de incertidumbre que se cierne sobre las posibles relaciones de Aristóteles y Alejandro, incide de forma particular la existencia de una carta del filósofo dirigida al monarca en la que trataría abiertamente de algunas de estas cuestiones, instándole mediante los consejos apropiados a afrontar debidamente la nueva etapa que se iniciaba tras su victoria sorprendente sobre los persas. ${ }^{34}$ No poseemos el original griego de la carta sino su traducción al árabe, que llamó ya particularmente la atención del arabista alemán del siglo XIX Julius Lippert, que la editó y la tradujo al latín difundiendo de este modo su conocimiento entre los estudiosos occidentales. El interés se acentuó a partir de los años sesenta del siglo $\mathrm{XX}$, cuando la carta en cuestión fue objeto de la edición y detenido comentario por parte de dos estudiosos polacos. ${ }^{35}$ La carta figura dentro de un conjunto conservado en los manuscritos Aya Sofia 4260 y Fatih 5323 del siglo XIV que contienen, además del epistolario mencionado, otra serie de textos que, en opinión de Mario Grignaschi, constituirían la versión árabe de una novela epistolar griega a cargo de Salim, el secretario del califato omeya en la primera mitad del siglo VIII d.C. ${ }^{36}$ Estas cartas figuran entre los primeros textos griegos traducidos al árabe, dado que la de los tratados filosóficos y científicos de Aristóteles se inició un siglo después. Curiosamente la Política no figura entre ellos, ya que nunca llegó a traducirse. La analogía entre la situación política de ambos momentos, el del imperio de Alejandro y la expansión

$31 \quad$ Arist. Pol. 1284 a.

32 G. W. F. Hegel, Geschichte der Philosophie, II, 404, citado en Ehrenberg 1938, 73, que analiza detenidamente dicho pasaje. Al respecto, también, Kelsen 1937 y Keyt 1991.

33 Ehrenberg 1938, 73-76.

34 Existen una traducción al francés en Bielawski - Plezia (1970), una al inglés en Stern (1968) y dos al italiano en Ingravalle (2013) y Cicoli - Moretti (2017).

35 La traducción al latín de Lippert (1891) y la edición posterior de Bielawski - Plezia (1970). Una edición más reciente en Sezgin (2000, 10-11). En general sobre las cartas de Aristóteles a Alejandro en versión árabe, Bielawski 1964; Maroth 2005; Di Branco 2011, 37-42.

36 Grignaschi 1996; Maroth 2005. Más recientemente, Cottrell 2016. 
omeya, explica el interés mostrado por esta cancillería, ya que los omeyas se veían obligados a organizar un imperio conquistado también de forma rápida y para ello era necesario tener en cuenta a las clases dirigentes de los vencidos, en particular los cuadros dirigentes persas del antiguo imperio sasánida. ${ }^{37}$

De las dieciséis cartas que constituyen el conjunto epistolar, quince son claramente apócrifas, tal y como se desprende de los evidentes anacronismos y de la total ausencia de verosimilitud. Consisten básicamente en reelaboraciones realizadas en época tardo-antigua basadas en parte sobre la denominada Novela de Alejandro atribuida al Pseudo Calístenes y sobre la tradición siríaca y medio persa que entran además frecuentemente en mutua contradicción. ${ }^{38} \mathrm{La}$ carta en cuestión, en cambio, se distingue del resto por la sobriedad de su estilo y por la aparente ausencia de anacronismos y aparece, además, ya citada en la literatura política árabe a partir del siglo VIII. La traducción latina de Lippert, basada en un solo manuscrito, el Vaticanus 408, que la dio a conocer a los medios occidentales, desató ya en su momento una importante polémica acerca de su autenticidad. Estudiosos como Heinrich Nissen o Alexander Pridik se decantaron a su favor frente a otros como Bruno Keil y Franz Susemihl, que la consideraron un ejercicio de retórica de época romana. ${ }^{39}$ Algunos estudiosos ilustres, como Ulrich Wilamowitz-Moellendorf, adoptaron una postura mucho más radical al respecto, afirmando con contundencia que no era necesario rebatir la autenticidad de la carta dado que Aristóteles no emitía palabras carentes de pensamiento (Worte ohne Gedanken), por lo que atribuía el texto a la misma categoría que el conocido Secretum Secretorum, una obra medieval de carácter heterogéneo situada entre el espejo de príncipes y una enciclopedia y tratado de moral. ${ }^{40}$

Las cosas parecieron cambiar notablemente cuando se descubrieron posteriormente en algunas bibliotecas de Estambul otros cinco manuscritos que contenían un texto de dicha carta más extenso que el que había presentado Lippert en su traducción latina, revelando de este modo que la versión ofrecida en el manuscrito vaticano utilizado en su día por el arabista alemán era solo un texto abreviado en el que se omitían varios pasajes importantes y un cierto número de nombres y de ejemplos históricos.$^{41}$ Se realizó entonces una edición del nuevo texto a cargo de los estudiosos polacos Josep Bielawski, arabista encargado de edición y de la traducción del texto al francés, y el helenista Marian Plezia, que llevó a cabo un detallado comentario del mismo. ${ }^{42}$ Otra edición, esta vez a cargo del arabista Samuel Stern y del helenista Oswyn Murray, no llegó a concretarse a causa de la inesperada desaparición del primero de ellos y hemos de contentarnos con algunos de los materiales utilizados para la misma que figuran en la reseña de la edición polaca redactada por el propio Murray. ${ }^{43}$ La polémica al respecto se desató de manera inmediata con destacados partidarios en cada uno de los dos bandos. Nombres señalados como los de James R. Hamilton, Pierre Thillet, Alain Houlou, Paul Goukowsky, Marta Sordi, Luisa Prandi, o Michele Faraguna, con sus correspondientes matices y diferencias, se han decantado

\footnotetext{
Gutas 2005, 53-54.

Di Branco 2011, 39, que remite sobre todo a Bielawski 1964 a este respecto.

Nissen 1892 y Pridik 1893; en contra, Keil 1892, 127-142 y Susemihl 1893. Acerca de la polémica en general, Stern 1968, 11-16.

40 Wilamowitz-Moellendorf 1893, I, 339. Sobre el Secretum Secretorum, Williams 2003.

$41 \quad$ Stern 1968, 17-24.

42 Bielawski - Plezia 1970. Véanse las reseñas de Von Fritz 1972 y de Montagu - Murray 1973.

43 Stern 1968 y Montagu - Murray 1973.
} 
por la autenticidad de la pieza en cuestión, ${ }^{44}$ mientras otros como Arnaldo Momigliano, Kurt Von Fritz, Marinus Wes, Pierre Carlier, Raymond Weil, Renato Laurenti y Carlo Natali se inclinan más bien por su carácter decididamente espurio..$^{45}$ Otros, como Mario Grignaschi y Miklos Maroth, la consideran simplemente un elemento más de una novela en la que las cartas ficticias desempeñan el soporte principal de la trama. ${ }^{46}$

Su principal valedor, Marian Plezia, ha desplegado un considerable esfuerzo para situar la carta dentro de un escenario consistente que permita ajustar convenientemente los argumentos de la filología, la filosofía y la historia. Ha intentado así establecer desesperadamente una serie de paralelismos más o menos sostenibles entre el texto de la carta y algunos pasajes determinados del corpus aristotélico con la idea de validar su autenticidad, e incluso ha llegado a identificar el texto con la obra Alejandro o sobre las colonias que figura en el elenco de las obras aristotélicas de Diógenes Laercio, de la que derivaría también el famoso fragmento aristotélico 658 de la edición de Rose, que nos ha llegado a través de los testimonios de Eratóstenes, por vía de Estrabón y de Plutarco. ${ }^{47} \mathrm{Su}$ fecha de composición habría que situarla, siguiendo también a los editores, poco después de la victoria de Gaugamela, tras la culminación aparente de la campaña de venganza con el licenciamiento de las tropas griegas en la primavera del 330 y antes de que Aristóteles hubiera tenido conocimiento de las purgas iniciadas por Alejandro entre su estado mayor, que en el curso de ese mismo año desembocaron en los asesinatos de Filotas y Parmenión. ${ }^{48}$ La referencia a la reciente captura de Babilonia, a la intención del monarca de continuar la campaña más allá de sus aparentes objetivos iniciales, y el tono exhortatorio del texto, que resultaría del todo inexplicable tras la aparente ruptura entre ambos que habría ocasionado la caída en desgracia de Calístenes y su muerte posterior, parecen apuntar efectivamente en esta dirección.

La carta constituye ciertamente un curioso documento en el que las constantes exhortaciones a la justicia y al comportamiento adecuado del gobernante respecto a sus súbditos se entremezclan con consideraciones más teóricas acerca de la estabilidad del gobierno y la importancia de las leyes para la continuidad y la prosperidad de los estados. A medio camino entre el tradicional espejo de príncipes y la carta de carácter admonitorio, el texto incluye tres aspectos fundamentales: las relaciones de Alejandro con los griegos, con los macedonios y con los bárbaros. El primero de los tres se concreta en la preocupación por conseguir un estado unificado en el que los griegos puedan vivir en concordia y amistad, sin guerras civiles ni discordias y dedicados por completo a la práctica de la filosofía, una vez conseguido el ansiado ideal de la paz. El segundo de ellos se deja sentir en la relación con sus súbditos, instando a tratarles de forma que no ofenda su dignidad y a conseguir el amor y la admiración como sustentos principales de la aceptación del poder y legitimidad del monarca, distinguiéndose en ello claramente de la práctica seguida por el soberano aqueménida y evitando el papel desestabilizador de los aduladores. Por último, se expresa la necesidad de deportar a las elites dirigentes persas con el fin de conseguir estabilidad y establecer la diferencia apropiada entre griegos y bárbaros dentro de un estado que

44 Hamilton 1969; Thillet 1972; Houlou 1973; Goukowsky 1978; Sordi 1984; Prandi 1984; Faraguna 2003.

45 Von Fritz 1972; Wes 1972; Momigliano 1975, 136-137; Carlier 1980; Weil 1985; Laurenti 1987; Natali 2013; Mazza 2013.

46 Grignaschi 1996; Maroth 2002-2003; 2005.

47 D.L. 5.22-27; Str. 1.4.9; Plu. Mor. 329 b. Sobre estos últimos pasajes, Badian 1958; Baldry 1965, 119-121.

48 Bielawski - Plezia 1970, 164. 
a pesar de la diversidad cultural y étnica debe descansar básicamente sobre un claro planteamiento de carácter panhelénico ${ }^{49}$.

La existencia de una correspondencia entre Aristóteles y Alejandro aparece atestiguada en la lista de obras atribuidas al filósofo en Diógenes Laercio, así como por las alusiones a la misma que figuran en otros autores como Demetrio de Falero, Cicerón, Eliano o Aulo Gelio. ${ }^{50}$ La carta parece adecuarse también relativamente bien a un contexto histórico determinado como son los momentos consecutivos a la decisiva victoria de Gaugamela lograda por Alejandro sobre el ejército persa de Darío III el 1 de octubre del 331 a.C., cuando parecía conseguido el objetivo principal de la campaña, si bien el deseo de Alejandro de emprender nuevas conquistas y la incorporación de las elites persas había originado también cierto malestar entre los macedonios. El cambio afectó también al perfil ideológico de la campaña y a su relación con los aliados. ${ }^{51}$ Parecía así el momento adecuado en el que insertar una intervención de este tipo, con consejos destinados a modelar (o reconducir) la conducta del monarca de acuerdo a unos esquemas teóricos de comportamiento que pudieron haber constado ya en el tratado sobre la realeza (Perí basileías), redactado posiblemente en el momento del acceso al trono macedonio por parte del joven príncipe ${ }^{52}$ Es muy probable que Aristóteles estuviera informado acerca de la deriva y evolución de Alejandro en el curso de la campaña mediante las noticias que podían llegarle, sobre todo a través de Calístenes, que seguramente ya en esos momentos debió mostrarse intensamente preocupado por la marcha de los acontecimientos y la correspondiente actitud del monarca. ${ }^{53}$

Aunque todo el discurso presente en la carta apenas alude a circunstancias y hechos concretos, con la excepción de la referencia inicial a la batalla de Gaugamela, y discurre por lo general dentro de un tono admonitorio sobre la manera adecuada de gobernar un imperio, podrían detectarse ciertamente algunas alusiones a los acontecimientos de entonces, como la exhortación a no encolerizarse contra aquellos que intentan rivalizar con sus esfuerzos o desean igualarle en dignidad y en grandes proyectos con el fin de evitar una abierta rebelión, que parece hacer referencia al creciente malestar de algunos miembros del estado mayor macedonio que luego acabaría desembocando en las conjuras de Filotas y los pajes o en el posterior asesinato de Clito el Negro. ${ }^{54}$ La idea acerca de la deportación de las elites persas, que tanto ha sorprendido a muchos de los críticos modernos, especialmente por su justificación mediante la aplicación de una desconocida hasta entonces Ley del Talión, referida aquí como el juicio de Radamantis, podría también hacer referencia a la situación de creciente complacencia del monarca con los vencidos, algunos de cuyos dirigentes comenzaban a adquirir cierto protagonismo dentro del estado mayor. El descontento ocasionado por tales medidas entre los propios macedonios y la supuesta actitud decididamente antipersa del filósofo, que habría sumado a su concepción general binaria de la humanidad escindida entre griegos y bárbaros el resentimiento personal

\footnotetext{
Un resumen de la carta en el apéndice de Carlier 1980 y en Cicoli - Moretti 2017, 79-88.

50 D.L. 5.1.22; Cic. Att. 12.40.2, 13.28.2; Demetr. Eloc. 234; Ael. VH 12.54; Gell. 20.5.12. Los testimonios aparecen traducidos en Ingravalle 2013, 57-64.

Poddighe 2009, 116.

Berti 1997, 36 .

Sobre las estrechas relaciones entre ambos personajes, Prandi 1985, 12-18.

546.4 en la traducción al francés de Bielawski - Plezia (1970) o 6 en la traducción al italiano de Cicoli - Moretti (2017).
} 
provocado por el trágico destino de su protector Hermias de Atarneo, asesinado a traición por los persas, avalarían esta decisión aparentemente excepcional.

Existe también una referencia a la denominada Liga de Corinto en un pasaje conflictivo a causa del topónimo $A l$ - Lada, que en la edición de Bielawski y Plezia se traducía como Libia, aludiendo de este modo a África y sus ciudades para que se unieran y se convirtieran así en una especie de ciudad única o como lugar de destino para la deportación de los persas junto con Europa. ${ }^{55}$ La alternativa propuesta en su día por Stern parece, sin embargo, la más adecuada, ya que interpreta el término como el topónimo Hélade en un caso oblicuo, lo que permite en las dos ocasiones en que aparece en la carta una interpretación mucho más factible, menos difícil de defender desde el punto de vista gramatical y mucho más satisfactoria desde la perspectiva histórica. ${ }^{56}$

Resulta igualmente significativa la alusión a las grandes conquistas realizadas gracias en parte al ejército que Alejandro había recibido de su padre, Filipo, en unos momentos en los que, a juzgar por lo sucedido durante el banquete de Maracanda en el que se produjo el asesinato de Clito el Negro, Alejandro trataba de marcar las distancias en este terreno con su antecesor, convirtiéndose dicha dicotomía en uno de los elementos determinantes del descontento general macedonio y en un claro signo del peligroso camino emprendido por el nuevo rey hacia una concepción bien diferente de la realeza. ${ }^{57}$ La imperiosa necesidad de establecer las diferencias con el monarca persa, en la que se incide en diferentes momentos de la carta, podría estar también relacionada con los evidentes peligros que podía comportar la asimilación de dicha figura extraña dentro de los esquemas políticos griegos. De ahí exhortaciones como la de ejercer el poder supremo sobre hombres libres en lugar de dominar esclavos, aunque fueran muy numerosos, conjugada con la combinación apropiada de justicia y clemencia con severidad y temor. ${ }^{58}$

Destaca también la alusión a la fundación de ciudades, que figura como uno de los tres pilares básicos que fundamentan un bello recuerdo y una gloria inmensa, a pesar de que en aquellos momentos no se había iniciado todavía -con la excepción de la Alejandría egipcia- la política de nuevos asentamientos urbanos que se desarrollaría más tarde durante la conquista de las denominadas satrapías superiores y de la India. A fin de cuentas, el autor de la carta, como habría hecho probablemente el propio Aristóteles, se mueve por completo dentro de los viejos esquemas griegos, como testimonian ampliamente sus referencias a las míticas legislaciones de las principales ciudades griegas, sus constantes alusiones al comportamiento detestable de los tiranos, la insistencia en mantener la paz y la concordia entre los griegos o la necesidad de crear esta clase de sustrato político en lo que aparecía ahora como un nuevo imperio de mayores dimensiones que debería englobar a todos los estados griegos. De cualquier modo, la concepción del imperio de Alejandro propuesta por el autor de la carta, que Bruno Keil calificaba como una especie de monarquía universal, parece del todo opuesta a las ideas del filósofo, tal y como subrayó en su día Pierre Carlier, que constataba la existencia de un abismo entre las concepciones del filósofo y la idea que aparece formulada en la carta. ${ }^{59}$

\footnotetext{
4.5 y 9.1 de la traducción francesa de Bielawski - Plezia (1970), que descartan Lidia como alternativa.

Von Fritz 1972, 448; Montagu - Murray 1973.

11.2 en la traducción al francés de Bielawski - Plezia (1970). Al respecto, Squillace 2004, 21-29.

12.10 y 13.6 en la traducción francesa de Bielawski - Plezia (1970).

Keil 1892, 136; Carlier 1980, 285.
} 
La concepción de un imperio universal que abarcase tanto a griegos como a bárbaros no parece desde luego una idea que cuadre con las que a este respecto podemos con seguridad atribuir a la paternidad del propio Aristóteles. ${ }^{60}$ El enfoque de toda la carta difiere igualmente por completo de lo expresado en los tratados aristotélicos conocidos, a pesar de la existencia de ciertas similitudes textuales con algunos pasajes de la Política o de la Ética a Nicómaco. ${ }^{61}$ La visión de un estado global en el que la polis se ve superada y engullida por una entidad políticamente superior no se encuentra por ninguna parte en las obras conservadas de Aristóteles. ${ }^{62}$ Aunque es básicamente cierto que, como ya se dijo, no existen los anacronismos manifiestos que suelen caracterizar esta clase de documentos de carácter ficticio, algunas de las menciones existentes en el texto, como la que hace referencia a un tal Atalo que habría desplazado a la población de Frigia de su territorio, no encuentran una fácil explicación por parte de los defensores de la autenticidad del documento que permita eludir las sospechas de una elaboración posterior. ${ }^{63}$ La referencia en la carta a la sucesión de los imperios llama igualmente la atención en este sentido, ya que hace su aparición en la literatura clásica a finales de la República romana y desde entonces es utilizada en los panegíricos de Roma que, después de Macedonia -que no figura lógicamente en la lista-, se convierte en el quinto y mayor de todos ellos. A ello se añade la utilización de determinados conceptos, como el de una ley común, un gobernante común y un imperio mundial, que aparecen estrechamente entrelazados en las alabanzas retóricas de Roma. ${ }^{64}$

\section{Aportación de la carta al debate}

La circunstancia de la pérdida del texto griego original y su conservación en una traducción al árabe condiciona por completo toda la cuestión. Como recordaba en su momento Renato Laurenti, "concludere da una traduzione è pericoloso" ${ }^{65}$ puesto que el texto de la carta no indica los nombres de aquellos personajes a los que alude, presenta los topónimos griegos y persas en una forma particular, dado su más que posible desconocimiento por parte de los traductores, que hace muy difícil el intento de recuperar su expresión original, e interpreta de modo inevitable algunos pasajes clave que resultan así mucho más problemáticos a la hora de entenderlos en su propio contexto intelectual y político, que no era, lógicamente, el de los traductores árabes encargados de la tarea. Es posible, además, que la traducción al árabe no haya sido directa desde el original griego, sino a través de un intermediario en siríaco, lo que

60 Badian 1958; Mazza 2013.

$61 \quad$ Natali 2013, 124.

62 Thillet 1972, 541-542.

639.9 en la traducción francesa de Bielawski - Plezia (1970). De hecho, el término "Frigia" es una corrección de los editores a la que parece la expresión presente en los manuscritos, Faranja "tierra de los francos", que remitiría inevitablemente a los francos y a una época posterior en la que dicho término resultaba familiar a los copistas árabes. El hecho de que no se encuentre en toda la literatura griega ninguna referencia al acontecimiento aludido podría ser indicativo. La mención del nombre Atalo parece también remitir a un período posterior, la época helenística, cuando los monarcas de este nombre de la dinastía atálida de Pérgamo tuvieron que hacer frente a la amenaza de los gálatas establecidos en el centro de la península anatolia. La solución ofrecida, basada en la tradición existente acerca de la llegada de los frigios a Asia Menor desde Tracia, una leyenda macedonia que hablaba sobre un héroe macedonio que derrotó a los frigios y los expulsó a Asia, no parece demasiado convincente. Stern 1968, 6, n.1.

64 Montagu - Murray 1973; Mazza 2013.

65 Laurenti 1987, 944-945. 
dificultaría todavía más el intento de alcanzar de la manera más precisa posible la formulación existente en el modelo original. ${ }^{66}$

La carta tampoco presenta una coherencia literaria destacada como para atribuirla a Aristóteles. Su estilo resulta un tanto repetitivo y los argumentos desplegados no se presentan del todo bien elaborados, tal y como se esperaría de su posible autor, si bien Bielawski y Plezia, perfectamente conscientes de estas circunstancias, las utilizan, en cambio, para reforzar su teoría acerca de la autenticidad del documento considerando que obedecen más bien a su carácter informal, lejano al de un tratado teórico, lo que avalaría de esta forma su carácter genuino. Sin embargo, lo cierto es que el carácter de la obra en general inspira poca confianza a pesar de lo bien fundadas que puedan resultar las argumentaciones a su favor desplegadas por una serie de estudiosos de primera fila. Da la impresión de formar parte del género literario de la carta admonitoria o de consejo, el llamado lógos sumbouleutikós o suasio en latín, del que tenemos constancia al menos a partir de Isócrates y que constituyó siempre un terreno proclive y fructífero para los falsarios. Bruno Keil la describió como una composición retórica acerca de las cualidades del gobernante ideal desde el punto de vista de sus súbditos. Kurt Von Fritz la consideró una mera compilación realizada por un individuo que conocía muy bien las obras de Aristóteles y especialmente los tratados Sobre la realeza y el Alejandro o sobre las colonias. Se desprendería de ello que, a pesar de no ser auténtica, la carta contendría material procedente de Aristóteles, circunstancia que habría contribuido de manera clara a afianzar su posición dentro del conjunto de este tipo de textos, claramente novelescos, y a destacar su singularidad en este terreno.

La idea de que Aristóteles permaneciera por completo ajeno al desarrollo de los acontecimientos que se estaban produciendo en aquellos momentos, con el avance imparable de las conquistas de Alejandro y la incorporación bajo sus dominios de nuevos y extensos territorios, y a sus posibles repercusiones sobre el panorama político griego parece efectivamente difícil de asumir. Podría alegarse en este sentido su confianza en la tutela ejercida sobre el monarca por su pariente y discípulo Calístenes, encargado de trasmitir al mundo griego la versión heroica y panhelénica de la campaña auspiciada por la propaganda real, al menos hasta los momentos que siguieron a la victoria de Gaugamela, manteniéndose así al corriente de los avances producidos en este sentido sin tener que molestarse en interferir de forma directa en la conducta de su antiguo pupilo. El importante cambio experimentado por la situación en aquellos momentos podría además justificar su intervención a través de la carta en lo que parecería un intento desesperado por mantener el imprevisible comportamiento de Alejandro dentro de los parámetros y esquemas de la politeía griega, centrada en la polis como referencia única y fundamental, pero situada ahora dentro de un mundo nuevo de horizontes mucho más amplios que demandaba urgentemente la emergencia de un nuevo modelo operativo. Esta circunstancia permitiría explicar las constantes referencias a la polis, a su forma de legislación, a los problemas derivados de la relación entre gobernantes y gobernados, o la insistencia a no incurrir en la tiranía, un tópico significativo que constituía además

66 Un aspecto importante en este terreno es el de la terminología empleada, que Plezia en su comentario intenta retrotraer hasta el griego con conclusiones discutibles al respecto. Existen también divergencias en la traducción del árabe, tal y como se reflejan en Montagu - Murray (1973), que tienen importantes consecuencias para la interpretación de determinados pasajes del texto. 
la pieza clave de la propaganda antimacedonia existente ya entre el mundo griego en aquel entonces, utilizada como uno de los argumentos fundamentales de sus numerosos adversarios. ${ }^{67}$

Todo parece así encajar a la perfección si se trata de asumir la autenticidad del texto de la carta, sobre todo dentro de un esquema que conserva intacta la imagen tradicional del magisterio casi continuado del filósofo sobre el monarca macedonio, tal y como supone el propio Plutarco y continúan defendiendo algunos estudiosos modernos, como por ejemplo Paul Faure, que consideraba que Aristóteles escribía al monarca para darle consejos. ${ }^{68} \mathrm{El}$ paso dado por Aristóteles se justificaría así por su deseo de afrontar una nueva situación que echaba completamente por tierra todos los viejos esquemas de su antiguo programa educativo y las consideraciones reflejadas en un tratado como la Política. El reinado de Filipo, con su unión forzosa de todos los estados griegos bajo su égida y sostenida constitucionalmente desde la perspectiva griega por el koinón de los helenos auspiciado en Corinto, había ya supuesto un cambio considerable en todo este panorama, pero las conquistas imparables de Alejandro y su integración de numerosas ciudades y reinos -además de extensos territorios y diferentes etnias- dentro de su naciente imperio abrían expectativas completamente nuevas ante las que un personaje de la talla y la curiosidad de Aristóteles no podía, teóricamente al menos, dejar de reaccionar de la forma adecuada, teniendo en cuenta que tales acontecimientos implicaban la completa puesta en entredicho de los esquemas tradicionales que regían sus especulaciones teóricas.

\section{Conclusiones}

La carta en cuestión no constituye, por tanto, una solución clara a todas estas fallidas expectativas. Las nuevas circunstancias del momento han dejado escaso reflejo en ella o se muestran al menos tímidamente desarrolladas para lo que cabría esperar a la vista de la situación. La carta no afronta de manera directa y decidida la nueva situación y continúa incidiendo en una dirección bien conocida que no parece dar más de sí, con las mencionadas exhortaciones a evitar incurrir en la tiranía y la llamada a asumir con sincero entusiasmo las cualidades personales y morales que debían caracterizar al gobernante ideal desde una perspectiva claramente griega. Sin embargo, Alejandro se había distanciado ya inevitablemente de aquellos parámetros y había iniciado una nueva etapa en la que los dictados de Aristóteles no parecen haber desempeñado un papel destacable a la hora de diseñar toda su estrategia política, que tenía como principal objetivo el dominio y control de un imperio de esta índole. Quizá el propio Aristóteles fue ya bien consciente de esta situación y decidió abandonar desde muy temprano cualquier tentativa de cambiar las cosas en este terreno, optando más bien por dedicar sus esfuerzos e intereses en otra dirección. Decidió así, quizá, aprovechar su oportuno retiro y la tranquilidad que le ofrecía su propia situación, buscando siempre desvincularse de la política del momento a la vista de los riesgos que podían comportar las nuevas circunstancias. De hecho, conocía bien la fallida experiencia de Platón en sus tentativas sicilianas y

\footnotetext{
67 Squillace 2004.

68 Faure 1985, 164-167.
} 
probablemente las tuvo muy en cuenta a la hora de constatar un más que probable nuevo fracaso, esta vez propio, en este tipo de azarosas empresas que pretendían convertir en filósofos a los gobernantes o a instarles decididamente a dejarse aconsejar por aquellos.

El autor de la carta, siguiendo posiblemente la estela de otros predecesores, pudo tratar, también a su manera, de rellenar el vacío documental acerca de las estrechas relaciones entre el monarca y el filósofo, una tarea que otros como Plutarco ya intentaron en su momento, y atribuyó al filósofo una intervención directa en el momento crucial de la campaña, recurriendo para ello a ideas bien sabidas y a consejos de índole general que podían aplicarse a estos momentos tan decisivos. La carta de Aristóteles, que, de admitir su autenticidad, podría haberse convertido en un testimonio clave con el que avalar la posible influencia ejercida por el filósofo griego sobre la conducta y el pensamiento del monarca macedonio, se convierte así en solo uno más de los muchos intentos que se hicieron por dar la consistencia adecuada a una relación personal y educativa que no cuenta, en cambio, con la documentación previsible. Los testimonios disponibles apuntan más bien en la dirección opuesta, la de un cierto abismo entre los dos personajes, que ya desde un principio parecían distanciados por completo en sus planteamientos y actitudes vitales.

No podemos tomar al pie de la letra ni conceder plena credibilidad a algunas informaciones que figuran en fuentes tardías, como Filodemo, que afirma que Aristóteles no intentó convertir a Alejandro a la filosofía, o Eusebio, que indica la preferencia de Alejandro por un tal Nicágoras, imitador de Hermes, en detrimento de Aristóteles, ${ }^{69}$ pero una y otra revelan posiblemente la conciencia existente en el ánimo de algunos estudiosos antiguos de esa sensación de distancia intelectual y, quizá, también afectiva que separaba de forma irremediable a los dos personajes. Los esfuerzos patentes de Plutarco por dar consistencia a una relación potencialmente explotable desde el punto de vista moral y educativo, seguidos después por otros estudiosos antiguos y modernos, entre los que la carta considerada desempeñaría un papel destacado, se mueven desgraciadamente dentro de las hipótesis más benevolentes que las evidencias disponibles -aunque tampoco resultan determinantes del todo- parecen contradecir a la vista de unas circunstancias poco favorables a sustentar una tutela intelectual que no produjo resultados efectivos.

\section{Referencias bibliográficas}

Asirvatham, S. R. (2018): “Plutarch's Alexander", [en] Moore, K. R. (ed.), Brill's Companion to the Reception of Alexander the Great, Leiden-Boston, 355-376 (http://dx.doi. org/10.1163/9789004359932_015).

Badian, E.

(1958): "Alexander the Great and the Unity of Mankind", Historia 7, 287-306.

(2012): Collected Papers on Alexander the Great, London (http://dx.doi. org/10.4324/9780203125267).

Baldry, H. C. (1965): The Unity of Mankind in Greek Thought, Cambridge (http://dx.doi. org/10.1017/CBO9780511735851).

${ }^{69}$ Eus. PE 15.2.4. Sobre Filodemo y Alejandro, Prandi 2016. Sobre el deterioro progresivo de las relaciones entre Alejandro y Aristóteles, Microyannakis 2016. 
Barnes, J. (1987): Aristóteles, Madrid.

Berti, E. (1997): La filosofia del "primo" Aristotele (=Università di Padova. Pubblicazioni della Facoltà di Lettere e filosofia 38), Milano.

Berve, H. (1926): Das Alexanderreich auf prosopographischer Grundlage, München, 2 vols.

Bielawski, J. (1964): "Lettres d'Aristote à Alexandre le Grand en version arabe", Rocznik Orientalistyczny/Yearbook of Oriental Studies 28, 1, 7-34.

Bielawski, J. - Plezia, M. (1970): Lettre d'Aristote à Alexandre sur la politique envers les cités (=Archiwum Filologiczne 25), Kraków.

Bretzl, H. (1903): Botanische Forschungen des Alexanderzuges, Leipzig.

Bröcker, M. (1966): Aristoteles als Alexanders Lehrer in der Legende, Bonn.

Brunt, P. (1993): Studies in Greek History and Thought, Oxford.

Carlier, P. (1980): “Étude sur la prétendue lettre d'Aristote à Alexandre transmise par plusieurs manuscrits arabes (I)", Ktema 5, 277-288.

Chiron, P. (2002): Pseudo-Aristote, Rhétorique à Alexandre, Paris.

Chroust, A. H. (1973): Aristotle. New Light on his Life and on some of his Lost Works, London.

Cicoli, F. - Moretti, F. (2017): Aristotele. Sull'Impero. Lettera ad Alessandro (=Mimesis 11), Milano.

Cottrell, E. (2016): “An Early Mirror for Princes and Manual for Secretaries: The Epistolary Novel of Aristotle and Alexander", [en] K. Nawotka-A. Wojciechowska (eds.), Alexander the Great and the East. History, Art, Tradition (=Philippika 103), Wiesbaden, 303-328 (http://dx.doi.org/10.2307/j.ctvckq3sm.24).

Di Branco, M. (2011): Alessandro Magno. Eroe arabo nel medioevo (=Piccoli saggi 49), Roma.

Düring, I. (1957): Aristotle in the Ancient Biographical Tradition (=Acta Universitatis Gothoburgensis 63; Studia Graeca et Latina Gothoburgensia 5), Göteborg.

Ehrenberg, V. (1938): Alexander and the Greeks, Oxford.

Faraguna, M. (2003): “Alexander and the Greeks”, [en] Roisman, (ed.), 2003, 99-130 (https:// doi.org/10.1163/9789004217553_005).

Faure, P. (1985): Alexandre, Paris.

Fraser, P. M. (1994): “The World of Theophrastus", [en] S. Hornblower (ed.), Greek Historiography, Oxford, 167-191.

Giannantoni, G. (1988): “Cinici e stoici su Alessandro Magno”, [en] G. Casertano (ed.), I filosofi e Il potere nella società e nella cultura antiche (=Acta Neapolitana 11), Napoli, 75-87.

Gigon, O.

(1958): "Interpretationen zu den Antiken Aristoteles-Viten", Museum Helveticum 15/3, 147-193.

(1987): Aristotelis opera, vol. III: librorum deperditorum fragmenta, Berlin.

Goukowsky, P. (1978): Essai sur les origines du mythe d'Alexandre. Tome I: Les origines politiques (=Annales de l'Est. Mémoire 60), Nancy.

Greenwalt, W. S. (2010): “Argead Dunasteia during the Reigns of Philip II and Alexander III”, [en] E. Carney - D. Ogden (eds.), Philip II and Alexander the Great. Father and Son. Lives and Afterlives, Oxford, 151-163.

Grignaschi, M. (1996): “Un roman épistolaire gréco-arabe: la correspondance entre Aristote et Alexandre", [en] M. Bridges - J. C. Bürge (eds.), The Problematics of Power. Eastern and Western Representations of Alexander the Great (=Schweizer Asiatische Studien. Monographien 22), Bern, 109-123.

Gutas, D. (2005): Pensée grecque, culture arabe, Paris (1ª ed. 1998).

Guthrie, W. C. K. (1993): Historia de la filosofía griega: vol. VI Introducción a Aristóteles, Madrid (1 ${ }^{\mathrm{a}}$ ed. Cambridge 1981). 
Hamilton, J. R.

(1961): "The Letters in Plutarch's Alexander", Proceedings of the Classical African Association 4, 9-20.

(1969): Plutarch Alexander, Oxford.

Hammond, N. G. L. (1993): Sources for Alexander the Great. An Analysis of Plutarch's Life and Arrian's Anabasis Alexandrou, Cambridge.

Houlou, A. (1973): “La conception du progrès dans l'Antiquité: à propos d'une lettre d'Aristote à Alexandre", [en] Actes du IX Congrès International de l'Association Guillaume Budé (Rome, 13-18 avril 1973), Roma, 978-994.

Ingravalle, F. (2013): Aristotele. Lettera ad Alessandro sul governo del mondo (=Minima Volti 39), Milano.

Jaeger, W. (1946): Aristóteles, México.

Keil, B. (1892): Die Solonische Verfassung in Aristoteles Verfassungsgeschichte Athens, Berlin.

Kelsen, H. (1937): "The Philosophy of Aristotle and the Hellenic-Macedonian Policy", The International Journal of Ethics 48, 1-64. http://dx.doi.org/10.1086/intejethi.48.1.2989300).

Keyt, D. (1991): “Aristotle's Theory of Distributive Justice", [en] D. Keyt - F. D. Miller (eds.), A Companion to Aristotle's Politics, Cambridge, 238-278.

Laurenti, R. (1987): Aristotele: I frammenti dei dialoghi (=Filosofi antichi 8-9), Napoli, 2 vols.

Liepert, J. (1891): De epistula pseudoaristotelica Perí Basileías commentatio, Berlin.

Maroth, M.

(2002-2003): "Political Theory in Ps.-Callisthenes and an Anonymous Arabic Novel of Letters", Acta Classica Universitatis Sientiarum Debrecenienseis 38-39, 150-168.

(2005): "The Correspondence between Aristotle and Alexander the Great. An Anonymous Greek Novel in Letters in Arabic Translation", Acta Antiqua Academiae Scientiarum Hungaricae 45, 231-315 (https://doi.org/10.1556/AAnt.45.2005.2-3.11).

Mazza, M. (2013): “L'atto di nascita dell'ellenismo? Qualche considerazione sulla c. d. lettera di Aristotele ad Alessandro sulla política verso le città", Studi Ellenistici 27, 29-43.

Mensching, E. (1963): "Die Peripatetiker über Alexander", Historia 12/3, 274-282.

Merlan, P. (1954): "Isocrates, Aristotle and Alexander the Great", Historia 3/1, 60-81.

Microyannakis, E. (2016): “Aristotle and Alexander: On the Gradual Deterioration of their Relationship", [en] O. Palagia - S. V. Tracy (eds.), The Macedonians in Athens, 322-229 B.C. Proceedings for the International Conference, Bloomigton, 37-39.

Momigliano, A. (1975): Alien Wisdom. The Limits of Hellenization, Cambridge.

Montagu, C. - Murray, O. (1973): “Aristotle. Lettre d'Aristote à Alexandre sur la politique envers les cités. Arabic text ed. and trans. J. Bielawski and M. Plezia. (Archiwum filologiczne, 25.) Wrocław: Polish Academy of Sciences. 1970. Pp. 206.2 plates. zł 50”, Journal of Hellenic Studies 93, 226-228 (https://doi.org/10.2307/631473).

Monti, G. (2016): "Le lettere di Alessandro: Storia degli studi”, Histos 10, 17-33.

Natali, C. (2013): Aristotle. His Life and School, Princeton.

Nissen, H. (1892): "Die Staatsschriften des Aristoteles", Rheinisches Museum für Philologie 47, 161-206.

Pearson, L. (1954): "The Diary and the Letters of Alexander the Great", Historia 3/4, 429455.

Pérez-Simon, M. (2010): "Le savant philosophe et le prince savant. Aristote et Alexandre le Grand", [en] P. Alexandre-Bergues - J. Guérin (eds.), Savoirs et savants dans la 
littérature (Moyen Âge-XXe siècle), (=Éditions Classiques Garnier, Rencontres 9), Paris, 17-33.

Plezia, M.

(1961): Aristotelis Epistolarum Fragmenta cum Testamento (=Auctorum Graecorum et Latinorum opuscula selecta, fasc. 3), Warszawa.

(1977): Aristotelis privatorum scriptorum fragmenta, Leipzig.

Poddighe, E. (2009): “Alexander and the Greeks. The Corinthian League”, [en] W. Heckel - L. A. Tritle (eds.), Alexander the Great. A New History, Oxford, 99-120.

Prandi, L.

(1984): "La lettera di Aristotele ad Alessandro: Il problema di Calistene", [en] M. Sordi (ed.), Alessandro Magno. Tra storia e mito, Milano, 31-45.

(1985): Callistene. Uno storico tra Aristotele e i re macedoni, Milano.

(1998): “Aristoteles und die Monarchie Alexanders (noch einmal zum 'arabischen' Brief)", [en] W. Schuller (ed.), Politische Theorie und Praxis im Altertum, Darmstadt, $72-84$.

(2016): "Philodemus of Gadara on Callisthenes and Alexander (New Light from PHer 1675 and 1050)", [en] C. Bearzot - F. Landucci (eds.), Alexander's Legacy. Atti del convegno, Milano Università cattolica del Sacro Cuore, settembre 2015, Roma, 203213.

Pridik, E. (1893): De Alexandri Magni epistularum commercio, Dorpat.

Reale, G. - Bos, A. P. (1995): Il Trattato sul cosmo per Alessandro attribuito ad Aristotele, Milano.

Roisman, J. (ed.), (2003): Brill's Companion to Alexander the Great, Leiden (https://doi. org/10.1163/9789004217553).

Romm, J. S. (1989): “Aristotle's Elephant and the Myth of Alexander Scientific Patronage”, American Journal of Philology 110/4, 566-575 (https://doi.org/10.2307/295280).

Rose, V. (1886): Aristotelis Fragmenta, Leipzig.

Ross, W. D. (1955): Aristotelis fragmenta selecta, Oxford.

Schachermeyr, F. (1949): Alexander der Grosse: Ingenium und Macht, Graz-Salzburgh-Wien.

Sezgin, F. (2000): Pseudo-Aristotelica preserved in Arabic translation, vol. I, De epistula pseudoaristotelica Perí basileías commentatio, Frankfurt am Main.

Sordi, M. (1984): "La lettera di Aristotele ad Alessandro e i rapporti tra greci e barbari", Aevum 58/1, 3-12.

Squillace, G. (2004): Basileís e túrannoi. Filippo II e Alessandro Magno tra opposizione e consenso (=Società antiche. Storia, culture, territori 6), Rubbbetino.

Stern, S. M. (1968): Aristotle on the World State, Columbia.

Stevens, K. (2016): "From Herodotus to a Hellenistic World? The Eastern Geographies of Aristotle and Theophrastus", [en] E. Barker - S. Bouzarovski - Ch. Pelling - L. Isaksen (eds.), New Worlds from Olds Texts. Revisiting Ancient Space and Place, Oxford, 121-152 (https://doi.org/10.1093/acprof:oso/9780199664139.003.0007).

Stoneman, R. (2003): “The Legacy of Alexander in Ancient Philosophy”, [en] Roisman (ed.), 2003, 325-345 (https://doi.org/10.1163/9789004217553_013).

Susemihl, F. (1893): "Literaturberich (zu Aristoteles)", Bursian Jahresberichte 75, 11-113.

Thillet, P. (1972): “Aristote conseiller politique d'Alexandre vainqueur des perses?", Révue des Études Grecques 85, 527-542 (https://doi.org/10.3406/reg.1972.1220).

Tierney, M. (1942): “Aristotle and Alexander the Great”, Studies. An Irish Quarterly Review of Letters Philosophy \& Science 31/122, 221-228. 
Von Fritz, K. (1972): “Aristotle on the World State by S. M. Stern; Lettre d'Aristote à Alexandre sur la politique envers les cites by Josep Bielawski and Marian Plezia", Gnomon 44, 442-45.

Weil, R.

(1960): Aristote et l'histoire. Essai sur la "Politique” (= Études et Commentaires 31), Paris.

(1985): "Sur la 'Lettre d'Aristote à Alexandre"”, [en] J. Wiesner (ed.), Aristoteles Werk und Wirkung: Paul Moraux gewidmet, Berlin, vol. I, 485-498.

Wes, M. A. (1972): “Quelques remarques à propos d'une 'lettre d'Aristote à Alexandre"”, Mnemosyne 25/3, 261-295 (https://doi.org/10.1163/156852572X00333).

Wilamowitz-Moellendorf, U. (1893): Aristoteles und Athen, Berlin.

Williams, S. J. (2003): The Secret of Secrets. The Scholarly Career of a Pseudo-Aristotelian Text in the Latin Middle Ages, Ann Arbor.

Worthington, I. (2008): Philip II of Macedonia, New Haven.

Zeller, E. (1879): Die Philosophie der Griechen in ihrer Geschichtlichten Entwicklung. Zweiter Teil, zweite Abtheilung. Aristoteles und die alten Peripatetiker, Leipzig. 